\title{
Community treatment orders and antipsychotic long-acting injections
}

Tim J. Lambert, Bruce S. Singh and Maxine X. Patel

\section{Background}

The community treatment order (CTO) is the legal framework by which people in the community are compelled to accept treatment. Both antipsychotic long-acting injections (LAIS) and CTOs are used to address treatment non-adherence.

\section{Aims \\ To investigate the relationship between CTOs and LAl use in patients with schizophrenia.}

\section{Method}

Prescribing, demographic and CTO data were collected for patients from four community mental health clinics in Melbourne, Australia, in 1998 and 2002.

\section{Results}

Against a background of increasing use of oral secondgeneration antipsychotic (SGA) medication and decreasing use of LAIs, the rates of CTO implementation doubled from $13 \%$ to $26 \%$ of patients with schizophrenia between 1998 and 2002. Proportionally more patients with a CTO are prescribed LAIs rather than oral SGAS.

\section{Conclusions}

The relationship between receiving an LAl and being subject to a CTO is significant, and reflects the consideration given to enhancing adherence in a community mental health setting.

\section{Declaration of interest}

M.P. has been reimbursed for attendance at scientific conferences and has received consultation fees from Janssen-Cilag and Eli Lilly; she has received investigatorinitiated grants from Janssen-Cilag and Eli Lilly and has previously worked on two clinical drug trials for JanssenCilag. T.L. has consulted to and received educational and research grants from Eli Lilly and Janssen-Cilag. B.S. has consulted to and received speaker's fees from Eli Lilly and Janssen-Cilag.
The community treatment order (CTO) is used to address medication non-adherence by provision of involuntary treatment but in a less restrictive environment than that afforded by in-patient care. These orders were first introduced in the USA in the mid-1970s and now are also available in several other countries. The CTO exists in different forms: for use immediately after a period of hospital detention; as an alternative to hospital detention; or to prevent deterioration before criteria for hospital detention are met. Other aspects of the CTO around the world also vary: duration (3 months or more); inclusion or exclusion of legal power to enforce medication in the community, requiring the police to escort the patient to hospital; ${ }^{1,2}$ eligibility criteria; ${ }^{3}$ and the person who is able to instigate the order (responsible clinician or formal judicial procedure involving a magistrate or judge).

\section{Clinical effectiveness of CTOs}

There have been two randomised controlled trials of CTOs; neither provided definitive evidence that CTOs are in themselves efficacious $^{1,4}$ and both had a number of problematic methodological issues. ${ }^{5-7} \mathrm{~A}$ recent Cochrane review pooled the data from the two trials and estimated that 85 people would need to receive a CTO in order to avoid one admission and that 238 people would need to receive a CTO in order to avoid one arrest. ${ }^{8}$ These numbers are substantially greater than one might expect. Further, a systematic review of over 70 studies concluded that CTOs lacked consistent evidence of benefit and that findings from naturalistic CTO studies were likely to be unreliable. ${ }^{9}$ Thus, to date there is a lack of rigorous evidence from randomised controlled trials to support the use of such orders. One might speculate that research in this area suffers from the difficulties that hamper research on long-acting injections (LAIs) - those required to participate are the least likely to consent and participate. In addition, the trials to date have taken place in North America, and the substantial differences in structure and function of community services in this setting compared with countries such as Australia and the UK might influence the substantial number needed to treat.

\section{Community treatment orders in the UK}

The UK has long debated the introduction of the CTO, particularly in relation to managing risk. ${ }^{10}$ Many regarded it as a 'toothless dragon' under previous legislation because 'the inability to allow enforced delivery of medications to patients is regarded by many as rendering CTOs ineffective. ${ }^{11}$ Since autumn 2008, under new legislation a CTO can be used after a patient has been detained under a hospital treatment order (Section 3) in England and Wales. ${ }^{12}$ Since 2005, Scotland has had community-based compulsory treatment orders (CCTOs). ${ }^{13}$ These can be applied either after detention in hospital, or de novo, usually as an alternative to a hospital order, but can only be instigated by the Mental Health Tribunal for Scotland. A number of disincentives exist in promoting their use in debatable cases and their rate of use is lower than in most other settings. ${ }^{14}$

\section{CTOs and antipsychotic long-acting injections}

In clinical practice the decision to prescribe either LAI or oral medication often rests largely on an assessment of the risk of poor adherence in the individual patient and what resources are available to deal with this. ${ }^{15-17}$ Long-acting injections are an attempt to overcome unknown or covert non-adherence by involving a clinician in administering the injection, although it should be noted that some patients may still actively be non-adherent to LAI treatment, either from the outset or later on. ${ }^{18,19}$ In essence, the principal function of the CTO might be then to encourage patients to accept instigation of an LAI, or simply to help reduce the high defaulting rate of patients already 
receiving an LAI. ${ }^{11,20,21}$ Others have also noted that the CTO works by 'persuading the persuadable' to engage in treatment. ${ }^{22}$

A number of studies in Australia have noted the particular relationship between LAIs and CTO administration. ${ }^{23-25}$ In an earlier study based in Victoria, CTO use was twice as likely with LAIs than with oral antipsychotics. ${ }^{23}$ As noted previously, there has been no clear signal to suggest that the use of a CTO with an LAI is particularly beneficial with respect to long-term outcomes. The CTO may first grant access to treating the patient with an LAI and also provide sufficient time to establish a regular injection routine. In turn, this allows patients a better chance of establishing some control over their illness and, with it, a measure of improved insight. This may enhance further adherence. ${ }^{26,27}$

The study reported here examines the changing trends in the use of CTOs and antipsychotic medications during the period of transition to full community treatment in Victoria, Australia. For patients with schizophrenia treated in the community we aimed, first, to estimate the rate of CTO use during the period 1998-2002 and, second, to understand its relationship to the prescription of LAI $v$. oral antipsychotics at both time points. We wished to determine whether the rate of use of CTOs significantly changed over this period, and to explore the balance of use of second-generation antipsychotics (SGAs) and firstgeneration antipsychotics (FGAs) in a healthcare system that was evolving to a full community-based model. We predicted that with the move to a fully deinstitutionalised model of care the rate of CTO use would increase, and that independently of changing trends in LAI and oral antipsychotic prescription rates, the prescribing of LAIs for patients on CTOs would be higher than that of oral antipsychotics.

\section{Method}

The study was conducted in community clinics of the NorthWestern Mental Health Programme (NWMHP) in urban Melbourne, Victoria, Australia. In the state of Victoria, CTOs are defined as 'orders under the Mental Health Act which enable involuntary patients to live in the community while they receive treatment for their mental illness. ${ }^{28}$ At the time of data collection the in-patient units in Victoria were described as being limited to providing intensive care, with 21.8 beds per 100000 adults and an average length of stay (estimated in 2001) of around 14 days (see Auditor General, Victoria 2002, in Brophy et al). ${ }^{29}$ Further, the study was undertaken during the closure of long-stay mental health hospitals and the development of mainstream, integrated community psychiatry service delivery. ${ }^{30}$ Thus, the only remaining acute in-patient units in the state of Victoria were in general medical hospitals. The transition was completed by the end of 2000 .

\section{Procedure}

As part of a larger project examining community-based antipsychotic treatment, ${ }^{31}$ prescribing and demographic information were obtained from four community mental health clinics of the NWMHP. The patient sample was a random selection of patients from each clinic's list of unique record locators. Where files were not available, a random replacement was selected from active files in the clinic. All case files were manually inspected for prescribing information and the results entered into a database. Information relating to CTO status was obtained from the NWMHP central administrative database and matched to patients by their unique record locator at each specific survey time point.

The sample in 1998 (time 1) was derived from 919 patients with schizophrenia sampled from the four community centres that were within the NWMHP administrative network, of whom 563 patients had meaningful data on CTO status available and also were known to be receiving antipsychotic treatment (excluding pro re nata, or as required, prescriptions). In 2002 (time 2) another random selection of cases from the same four clinics provided 1142 patients with schizophrenia, of whom 806 had a valid active antipsychotic prescription and a matched record of their current CTO status.

\section{Statistical analysis}

For analyses of the relationship between CTO use and antipsychotic prescription, those receiving antipsychotic LAIs (either as monotherapy or in combination with other antipsychotics) were contrasted with all prescriptions for antipsychotics not involving an LAI. For SGA-oral analysis, these agents were compared with LAIs and FGA-orals. As a small number of patients at both time points were receiving both SGA-oral and FGA-LAI therapy, the analysis of the relationship of CTO patients to SGA-oral use was undertaken after exclusion of the patients also receiving an FGA-LAI (time 1: $n=9,2.4 \%$ reduction in sample size; time 2: $n=59,7 \%$ reduction in sample size). Analyses of categorical data employed chi-squared analysis. Where interval or ratio data were normally distributed, $t$-tests were used. Tests of proportions were calculated using the binomial test. Simple odds ratios were computed using Cochrane's and Mantel-Haenszel statistics.

\section{Results}

Demographic information at time 1 is shown in Table 1 . The cross-sectional use of a CTO was unrelated to any demographic variable, other than the treating clinical centre, with one clinic using CTOs in $20 \%$ of its patients with schizophrenia, in contrast to $8-13 \%$ in the other clinics $(P=0.027)$.

\section{Rates of Сто use}

For patients with schizophrenia who were prescribed an antipsychotic, the rate of CTO use was $13 \%(74 / 563)$ at time 1 and $26 \%(209 / 806)$ at time 2 . The increase in the proportion of patients with a CTO over this period was significant (time $1 \mathrm{v}$. time 2, binomial $P<0.001$ ) (Fig. 1).

\section{Oral antipsychotics $v$. LAls}

The relationship between the use of CTOs and the prescription of LAIs is shown in Table 2. In 1998, of the $13 \%$ of patients given a CTO, $77 \%(n=57)$ were prescribed an LAI, in contrast to the $23 \%(n=17)$ who were prescribed only oral antipsychotics. At this time for a patient with a CTO the odds of being prescribed an LAI were 4.7 times that of being prescribed only an oral antipsychotic. In 2002, of the $26 \%$ of patients given a CTO, $47 \%$ were prescribed an LAI and 53\% were prescribed an oral antipsychotic only. This indicates that although the use of CTOs is split almost equally between LAI and oral drugs, the odds of having a CTO with an LAI are 3.2 times those of having a CTO with an oral antipsychotic.

For all patients with schizophrenia treated with antipsychotic medication, Fig. 1 shows the changes in CTO and formulation use between 1998 and 2002. It is notable that the CTO rate was increasing, along with a decrease in the use of FGA-LAIs and an increase in numbers of patients treated with oral formulations only. However, as a proportion of all antipsychotic-treated patients at each time point, the rate of patients on a CTO with an FGA-LAI remained reasonably stable (10\% in 1998 and $12 \%$ in 2002). This is in contrast to the patients on a CTO with oral 


\begin{tabular}{|c|c|c|c|c|}
\hline & $\begin{array}{c}\text { All } \\
n(\%)\end{array}$ & $\begin{array}{c}\text { NO CTO } \\
n(\%)\end{array}$ & $\begin{array}{c}\text { On CTO } \\
n(\%)\end{array}$ & Significance \\
\hline \multicolumn{5}{|l|}{ Gender } \\
\hline Female & 219 (39) & 192 (39) & $27(38)$ & \multirow{3}{*}{$\begin{array}{l}\chi^{2}=0.03 \\
P=0.865\end{array}$} \\
\hline Male & $341(61)$ & $296(61)$ & $45(62)$ & \\
\hline Total $^{a}$ & $560(100)$ & $488(87)$ & $72(13)$ & \\
\hline \multicolumn{5}{|l|}{ Age } \\
\hline$<30$ years & $164(29)$ & $142(30)$ & $22(31)$ & \multirow{3}{*}{$\begin{array}{l}\chi^{2}=0.01 \\
P=0.917\end{array}$} \\
\hline$\geqslant 30$ years & $395(71)$ & $345(71)$ & $50(69)$ & \\
\hline Total & $559(100)$ & $487(87)$ & $72(13)$ & \\
\hline \multicolumn{5}{|l|}{ Marital status } \\
\hline $\begin{array}{l}\text { Previous or current } \\
\text { relations }\end{array}$ & $207(40)$ & $181(40)$ & $26(39)$ & \multirow{3}{*}{$\begin{array}{l}\chi^{2}=0.01 \\
P=0.999\end{array}$} \\
\hline Never married & $313(60)$ & $273(60)$ & $40(61)$ & \\
\hline Total & $520(100)$ & $454(87)$ & $66(13)$ & \\
\hline \multicolumn{5}{|l|}{ Ethnicity } \\
\hline English-speaking COB & $328(62)$ & $286(62)$ & $42(65)$ & \multirow{3}{*}{$\begin{array}{l}\chi^{2}=0.08 \\
P=0.775\end{array}$} \\
\hline NESB COB & $199(38)$ & $176(38)$ & $23(35)$ & \\
\hline Total & $527(100)$ & $462(88)$ & $65(12)$ & \\
\hline \multicolumn{5}{|l|}{ Benefits } \\
\hline No pension & 49 (9) & $46(10)$ & $3(4)$ & \multirow{3}{*}{$\begin{array}{c}\text { Fisher's } \\
\chi=0.18 \\
P=0.105\end{array}$} \\
\hline Pension or benefits & $495(91)$ & $429(92)$ & $66(96)$ & \\
\hline Total & $544(100)$ & $475(87)$ & 69 (13) & \\
\hline \multicolumn{5}{|l|}{ Accommodation } \\
\hline Independent & $469(86)$ & $414(87)$ & $55(80)$ & \multirow{3}{*}{$\begin{array}{l}\chi^{2}=2.22 \\
P=0.136\end{array}$} \\
\hline Supported/homeless & 75 (14) & $61(13)$ & $14(20)$ & \\
\hline Total & $544(100)$ & $475(87)$ & 69 (13) & \\
\hline \multicolumn{5}{|l|}{ Education } \\
\hline Primary or secondary & $344(83)$ & $303(82)$ & $41(89)$ & \multirow{3}{*}{$\begin{array}{c}\text { Fisher's } \\
\chi=0.30 \\
P=0.154\end{array}$} \\
\hline Tertiary & $72(17)$ & $67(18)$ & $5(11)$ & \\
\hline Total & $416(100)$ & $370(89)$ & $46(11)$ & \\
\hline \multicolumn{5}{|l|}{ Clinic } \\
\hline A & $135(24)$ & $117(24)$ & $18(25)$ & \multirow{5}{*}{$\begin{array}{l}\chi^{2}=9.14 \\
P=0.027\end{array}$} \\
\hline B & $157(28)$ & $140(29)$ & $17(24)$ & \\
\hline C & $144(26)$ & $132(27)$ & $12(17)$ & \\
\hline D & $124(22)$ & $99(20)$ & $25(35)$ & \\
\hline Total & $560(100)$ & $488(87)$ & $72(13)$ & \\
\hline
\end{tabular}

COB, country of birth; CTO, community treatment order; NESB, non-English-speaking background.

a. Of the 563 patients, 3 had missing demographic data. medication only, where the respective rates were $3 \%$ of all patients in 1998 and $14 \%$ in 2002.

\section{Oral SGAs v. FGAs (oral and LAI)}

Table 3 shows the relationship between the use of CTOs and the prescription of oral SGAs. In the period between 1998 and 2002, SGA-oral prescriptions grew from $33 \%$ to $74 \%$. Excluding patients with polypharmacy of an SGA-oral with an FGA-LAI, $13 \%$ of patients at time 1 had a CTO; of these, $14 \%$ were treated with an SGA-oral and the other 86\% were treated with an FGA (oral or LAI). At time 2 a quarter $(26 \%)$ of patients had a CTO; of these, 54\% were prescribed an SGA-oral and the other $46 \%$ were treated with an FGA (oral or LAI). However, in keeping with the analysis presented above, it is significantly less likely that patients given a CTO will receive an SGA-oral rather than an FGA (oral or LAI) when compared with those not given a CTO.

\section{Discussion}

In 1998 in the NWMHP catchment area in urban Melbourne, 13\% of patients with schizophrenia were subject to a CTO. This is consistent with the findings of others for this region. ${ }^{23,24}$ This rate doubled over the subsequent 4 years, so that by 2002 a quarter of

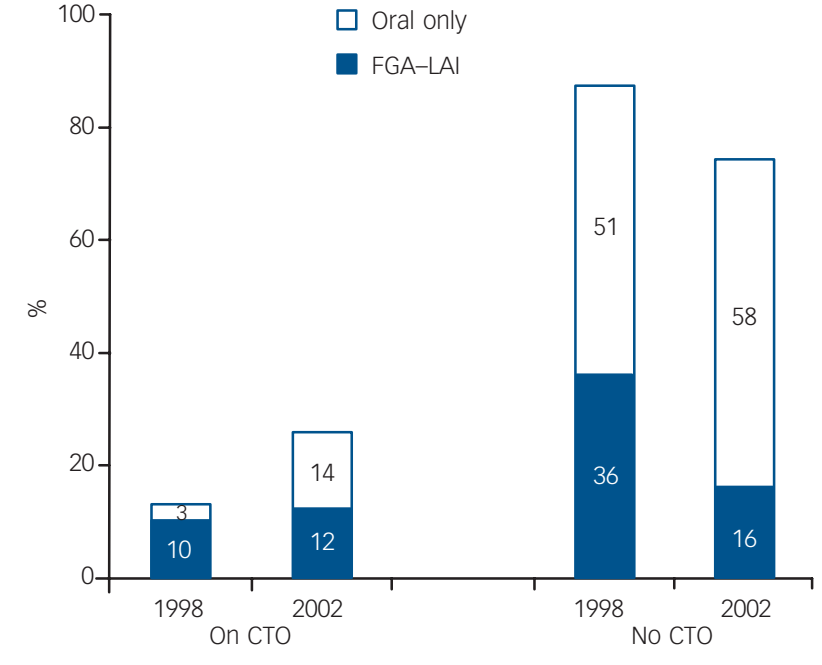

Fig. 1 Proportion of patients with schizophrenia according to community treatment order (CTO) status and antipsychotic

formulation (FGA, first-generation antipsychotic).

\begin{tabular}{|c|c|c|c|c|}
\hline & $\begin{array}{c}\text { All } \\
n(\%)\end{array}$ & $\begin{array}{c}\text { No сто } \\
n(\%)\end{array}$ & $\begin{array}{c}\text { On сто } \\
n(\%)\end{array}$ & OR $(95 \% \mathrm{Cl})^{\mathrm{a}}$ \\
\hline \multicolumn{5}{|l|}{1998} \\
\hline Oral only & $302(54)$ & $285(58)$ & $17(23)$ & $4.68(2.65-8.29)$ \\
\hline FGA-LAl & $261(46)$ & $204(42)$ & 57 (77) & \\
\hline Total & $563(100)$ & $489(87)$ & $74(13)$ & \\
\hline \multicolumn{5}{|l|}{2002} \\
\hline Oral only & $575(71)$ & $465(78)$ & $110(53)$ & $3.17(2.27-4.43)$ \\
\hline FGA-LAl & 231 (29) & $132(22)$ & $99(47)$ & \\
\hline Total & $806(100)$ & $597(74)$ & $209(26)$ & \\
\hline
\end{tabular}

CTO, community treatment order; FGA, first-generation antipsychotic; LAI, long-acting injection

a. FGA-LAI ( oral) V. oral antipsychotics only (first or second generation).

\begin{tabular}{|c|c|c|c|c|}
\hline & $\begin{array}{c}\text { All } \\
n(\%)\end{array}$ & $\begin{array}{c}\text { No CTO } \\
n(\%)\end{array}$ & $\begin{array}{c}\text { On СТO } \\
n(\%)\end{array}$ & OR $(95 \% \mathrm{Cl})^{\mathrm{a}}$ \\
\hline \multicolumn{5}{|l|}{1998} \\
\hline FGA (oral or LAI) & $373(67)$ & $312(65)$ & $61(86)$ & \\
\hline SGA-oral & 181 (33) & $171(35)$ & $10(14)$ & \\
\hline Total & $554(100)$ & $483(87)$ & $71(13)$ & $0.30(0.15-0.60)$ \\
\hline \multicolumn{5}{|l|}{2002} \\
\hline FGA (oral or LAl) & $198(26)$ & $110(20)$ & $88(46)$ & \\
\hline SGA-oral & $549(74)$ & $445(80)$ & $104(54)$ & \\
\hline Total & 747 (100) & $555(74)$ & $192(26)$ & $0.29(0.21-0.42)$ \\
\hline
\end{tabular}

patients with schizophrenia were on CTOs. This occurred in the final phase of transition from a traditional hospital-based service delivery system to a more community-based system, with a small number of short-term acute psychiatric beds. ${ }^{32}$ Despite a changing balance in the type of antipsychotics prescribed, the 
association between CTOs and LAIs remained strong throughout the study. By 2002 just under half of those on CTOs were also prescribed an LAI. In essence, as a proportion of all antipsychotictreated patients at each time point, the rate of patients subject to a CTO with an LAI remained relatively stable over time. In 1998, of the patients receiving a CTO, three-quarters were prescribed an LAI, but in 2002, of those receiving a CTO only slightly less than half were prescribed an LAI. Thus, there was a reduction in the proportion of patients on CTOs who were also prescribed an LAI, but it still remained relatively high. It is likely that LAI prescribing is, in the main, a clinician response to poor adherence and that the CTO is the mechanism used to compel reluctant patients to take the injection. Two main aspects regarding use of an LAI with a CTO include the changing treatment patterns for schizophrenia and the nature of psychiatric service provision.

\section{Effect of changing treatment patterns}

With the demonstrated trend towards the use of oral SGAs, it is likely that those who could have been switched to and successfully maintained on SGA-orals would have done so. Thus, those remaining on LAIs may represent a particularly difficult group of patients. The actively and assiduously non-adherent patient may require a CTO in order to have any chance of commencing an LAI. Such patients may be more difficult, more reluctant to accept treatment, and have longer, more established histories consistent with 'revolving door' characteristics. In such circumstances, there may be a requirement for the added 'authority to treat' associated with the use of CTOs to be applied in order for patients to accept their LAI injections.

Given that the rate of LAI use fell from $46 \%$ to $29 \%$, more marginal cases that might have been treated with LAIs in the pre-SGA era might instead have been given the benefit of the doubt and treated with an oral SGA in the expectation of improved outcomes. Although by 2002, given the increase in SGA-oral prescribing in general and the expected risks of oral non-adherence, the increase in use of CTOs with SGA-orals was lower than might otherwise have been expected. This may reflect the difficulty of accurately assessing non-adherence to oral medication regimens. ${ }^{18}$ Thus, the threshold for revoking the CTO and returning the oral SGA-treated patient to hospital is less clear-cut, and there will be considerable reluctance to revoke a CTO merely on the suspicion that patients are not taking their oral medication.

\section{Service and community aspects of СТО use}

One criticism of the CTO is that when patients subject to an order refuse to take their medication (i.e. non-adherence) forced treatment in the community does not necessarily follow, as seen in the USA. ${ }^{4}$ In the state of Victoria, revoking a CTO allows for the patient to be returned to hospital. However, this occurs mainly for florid relapse and only rarely to ensure treatment adherence. Arguably, CTOs are most successful when patients perceive (if erroneously) that they can be treated against their wishes outside the hospital setting. ${ }^{33}$ This remains a form of coercion over and above the legislation itself. Hence, CTOs may serve to 'persuade the persuadable', in the hope that the patient does not test the resolve of the community teams to rescind the CTO for breaches relating to non-adherence. ${ }^{11,20,34}$ Although it is uncommon, patients who have known risk histories and who refuse their injections may have their CTO revoked, be admitted to hospital for the injection, and then discharged immediately. This may be because in all countries with CTO legislation, public safety has been a part of the justification for CTO instigation, and this may be considered over and above the needs of the individual patient. $^{35}$

The increase in the use of CTOs in the face of reductions in hospital beds may be an understandable reaction by clinicians. However, this does not tell us whether the increase in CTOs actually reduced relapse rates through increased adherence or enhanced the perception of public safety. Further, it has been noted that changes in CTO law do not translate simply into changes in practice, particularly where entrenched positions exist among those charged with carrying out CTO policy at the level of community mental health services. ${ }^{9,33}$

\section{The future of long-acting injections and CTOs}

Thus far, the evidence for enduring LAI adherence due to the administration of a CTO is minimal, as seen in a related study by Lambert et al. ${ }^{36}$ That study showed that when 1-year LAI adherence was examined using a multivariate model comprising known associations of LAI adherence, CTOs did not remain in the final model when predicting adherence; $55 \%$ of the study cohort were on CTOs. Similarly, in the larger of the two randomised controlled trials on this topic, patients on an LAI were 2.5 times more likely to be adherent to treatment, but this was independent of the CTO effect. ${ }^{34}$ Measuring effectiveness of LAIs in comparison to oral formulations is also pertinent, ${ }^{19,37}$ and we suggest studies of at least 2 years' duration are required for investigation of LAI use in combination with a CTO. Directions for future research include:

(a) the role of the CTO in maintaining medication treatment adherence;

(b) identification of the best outcome measure for effectiveness of CTOs (relapse or other) ${ }^{38}$

(c) identification of characteristics of the patients most likely to benefit from a $\mathrm{CTO} ;{ }^{29}$

(d) comparisons of SGA-oral $v$. LAI (FGA and SGA), both with or without use of a CTO;

(e) optimal duration of the CTO;

(f) enduring duration of treatment adherence and clinical benefits beyond the expiry of the CTO.

\section{Limitations}

One limitation of our study relates to its dependence on administrative databases for CTO data. It is possible that the bias may be towards overestimating the proportion of patients receiving CTOs. However, given that the rates were similar to other studies reported in Victoria at this time (which did not depend on a centralised database), and also given that the structure of services is mandated to be consistent throughout Victoria, any such bias is likely to be minimal. There also exists a problem in acquiring demographic data from case-file systems. Missing data due to technical and administrative problems may bias the relationships between key variables. Also, there was no measure of illness duration, number of previous hospitalisations or dangerousness available for analysis, which might be thought to influence CTO use. One should also consider that the CTO in the state of Victoria is relatively easy to apply - there is no magistrate or judicial process involved, and this may bias the estimates of the frequency of its use compared with other systems.

The generalisability of our findings to other settings such as the UK is limited by the fact that SGA-LAIs were not available at the time of data collection and that oral SGAs are now better understood in terms of their different side-effect profiles (with 
somewhat enhanced risk of developing metabolic syndrome). These developments may potentially alter the rates of concomitant use of LAIs and CTOs, although in which direction would be subject to further enquiry.

\section{Implications of the study}

Community treatment orders provide a mechanism for involuntary treatment beyond the hospital setting. The proportion of patients on such orders increased during the observation period (1998-2002) such that by 2002 a quarter of patients with schizophrenia were receiving CTOs. This took place in a system with several years' experience of the CTO but during a time when the last of the long-stay in-patient beds were closed.

The most consistent association with CTO use is the prescription of antipsychotic LAIs, and both are used in the management of treatment non-adherence. For patients subject to a CTO, an LAI is more than twice as likely to be prescribed as an oral antipsychotic. Thus, as a proportion of all antipsychotic-treated patients at each time point, the rate of patients with a CTO prescribed an FGA-LAI remained relatively stable. That said, the proportion of patients given a CTO who were also prescribed an FGA-LAI declined over time, but remained high (Fig. 1). This is despite the general trends in prescribing for schizophrenia whereby the proportion of SGA-orals increased and that of LAIs decreased. Even with the advent of SGA-orals, the use of CTOs remains strongly associated with the prescription of LAIs relative to oral medications.

Long-acting antipsychotic injections have been described as potentially 'the best authenticated method of preventing relapse in non-adherent, or forgetful patients, ${ }^{39}$ but defining those who specifically require the added measure of a CTO requires further elucidation. With increasing uptake of CTO legislation as found in England and Wales, whether LAIs (first- and second-generation) will be as preferentially chosen over oral antipsychotics remains to be seen.

\section{Acknowledgements}

We thank Drs Mark Taylor and Donald Lyons, who provided information regarding use of the community treatment order in Scotland, Professor George Szmukler for comments on earlier drafts of this paper, and Ms Joyce Goh, who facilitated the acquisition of the on earlier drafts of this
CTO data in Melbourne.

Tim J. Lambert, BSC, MBBS, PhD, FRANZCP, Discipline of Psychological Medicine, Brain and Mind Research Institute, University of Sydney, Camperdown, New South Wales; Bruce S. Singh, MBBS, PhD, FRACP, FRANZCP, Department of Psychiatry, Faculty of Medicine, Dentistry and Health Sciences, University of Melbourne, Parkville Victoria, Australia; Maxine X. Patel, BSC, MSC, MBBS, MRCPsych, Division of Psychological Medicine, Institute of Psychiatry, King's College London, UK

Correspondence: Dr Maxine Patel, Division of Psychological Medicine Box 68, Institute of Psychiatry, King's College London, De Crespigny Park, London SE5 8AF, UK. Email: m. patel@iop.kcl.ac.uk

\section{References}

1 Swartz MS, Swanson JW, Wagner HR, Burns BJ, Hiday VA, Borum R. Can involuntary outpatient commitment reduce hospital recidivism? Findings from a randomized trial with severely mentally ill individuals. Am J Psychiatry 1999; 156: 1968-75.

2 Torrey EF, Kaplan RJ. A national survey of the use of outpatient commitment Psychiatr Serv 1995; 46: 778-84.

3 Gray JE, O'Reilly RL. Canadian compulsory community treatment laws: recent reforms. Int J Law Psychiatry 2005; 28: 13-22.

4 Steadman HJ, Gounis K, Dennis D, Hopper K, Roche B, Swartz M, et al. Assessing the New York City involuntary outpatient commitment pilot program. Psychiatr Serv 2001; 52: 330-6.
5 Swartz MS, Swanson JW. Involuntary outpatient commitment, community treatment orders, and assisted outpatient treatment: what's in the data? Can J Psychiatry 2004; 49: 585-91.

6 Szmukler G, Hotopf M. Effectiveness of involuntary outpatient commitment. Am J Psychiatry 2001; 158: 653-4.

7 O'Reilly R, Bishop J. Assessing the New York City involuntary outpatient treatment program. Psychiatr Serv 2001; 52: 1533-4.

8 Kisely S, Campbell LA, Preston N. Compulsory community and involuntary outpatient treatment for people with severe mental disorders. Cochrane Database Syst Rev 2005; (3): CD004408.

9 Churchill R, Owen D, Singh S, Hotopf M. International Experiences of Using Community Treatment Orders. UK Department of Health, 2007.

10 Sensky T, Hughes T, Hirsch S. Compulsory psychiatric treatment in the community. II. A controlled study of patients whom psychiatrists would recommend for compulsory treatment in the community. $\mathrm{Br} J$ Psychiatry 1991; 158: 799-804.

11 Ridley G. Community treatment orders. Br J Psychiatry 1993; 163: 417.

12 Department of Health. Mental Health Act 2007. UK Department of Health, 2007 (http://www.opsi.gov.uk/acts/acts2007/pdf/ukpga_20070012_en.pdf).

13 Mental Welfare Commission for Scotland. Annual Report to Members. Mental Welfare Commission for Scotland, 2007 (http://www.kingsfund.org.uk/ publications/kings_fund_publications/a_question_of_1.html).

14 Lawton-Smith S. A Question of Numbers: The Potential Impact of Community-Based Treatment Orders in England and Wales. King's Fund, 2007 (http://www.kingsfund.org.uk/publications/kings_fund_publications/ a_question_of_1.html).

15 Barnes TRE, Curson DA. Long-term depot antipsychotics: a risk-benefit assessment. Drug Saf 1994; 10: 464-79.

16 Davis JM, Matalon L, Watanabe MD, Blake L, Matalon L. Depot antipsychotic drugs. Place in therapy. Drugs 1994; 47: 741-73.

17 Dignam P. Ethics of community treatment orders (letter). Aust $\mathrm{N} Z \mathrm{~J}$ Psychiatry 1998; 32: 890 .

18 Levine J, Schooler NR, Cassano GB. The role of depot neuroleptics in the treatment of schizophrenic patients. Psychol Med 1979; 9: 383-6.

19 Patel MX, David AS. Why aren't depot antipsychotics prescribed more often and what can be done about it? Advan Psychiatr Treat 2005; 11: 203-11.

20 Hardman AE. Community treatment order in Australia. Br J Psychiatry 1993; 162: 710 .

21 McLaren S, Cookson J. Community treatment orders for mental illness (letter). Lancet 1989; ii: 1457

22 Pinfold V, Bindman J, Thornicroft G, Franklin D, Hatfield B. Persuading the persuadable: evaluating compulsory treatment in England using Supervised Discharge Orders. Soc Psychiatry Psychiatr Epidemiol 2001; 36: 260-6.

23 Callaly $T$, Trauer T. Patterns of use of antipsychotic medication in a regional community mental health service. Australas Psychiatry 2000; 8: 220-4.

24 Vaughan $\mathrm{K}$, McConaghy $\mathrm{N}$, Wolf $\mathrm{C}$, Myhr $\mathrm{C}$, Black T. Community treatment orders: relationship to clinical care, medication compliance, behavioural disturbance and readmission. Aust N Z J Psychiatry 2000; 34: 801-8.

25 Muirhead DR, Ingram G, Harvey C. Effectiveness of community treatment orders for treatment of schizophrenia with oral or depot antipsychotic medication: clinical outcomes. Aust N Z J Psychiatry 2006; 40: 596-605.

26 Cuffel BJ, Alford J, Fischer EP, Owen RR. Awareness of illness in schizophrenia and outpatient treatment adherence. J Nerv Ment Dis 1996; 184: 653-9.

27 Garavan J, Browne S, Gervin M, Lane A, Larkin C, O'Callaghan E. Compliance with neuroleptic medication in outpatients with schizophrenia; relationship to subjective response to neuroleptics; attitudes to medication and insight. Compr Psychiatry 1998; 39: 215-9.

28 Department of Human Services. Involuntary Patients. About Your Rights. Mental Health Branch, Victorian Government Dept of Human Services, 2004.

29 Brophy LM, Reece JE, McDermott F. A cluster analysis of people on Community Treatment Orders in Victoria, Australia. Int J Law Psychiatry 2006; 29: 469-81.

30 Singh BS. Mainstreaming psychiatric services. Med J Australia 1992; 156: 373-4.

31 Lambert TJR. The use of depot antipsychotics in community psychiatry. PhD dissertation, University of Melbourne, 2005.

32 Goldberg D. Impressions of psychiatry in Australia. Australas Psychiatry 2000; 8: $307-11$.

33 Dawson J. Fault-lines in community treatment order legislation. Int J Law Psychiatry 2006; 29: 482-94.

34 Swartz MS, Swanson JW, Wagner HR, Burns BJ, Hiday VA. Effects of involuntary outpatient commitment and depot antipsychotics on treatment 
adherence in persons with severe mental illness. J Nerv Ment Dis 2001; 189 583-92.

35 Appelbaum PS. Law and psychiatry: dangerous persons, moral panic, and the uses of psychiatry. Psychiatr Serv 2003; 54: 441-2.

36 Lambert T, de Castella A, Kulkarni J, Ong AN, Singh B. One year estimate of depot antipsychotic adherence and readmission in Australian community mental health settings. Schizophr Bull 2007; 33: 485.

37 Hogarty GE, Schooler NR, Ulrich R, Mussare F, Ferro P, Herron E. Fluphenazine and social therapy in the aftercare of schizophrenic patients. Relapse analyses of a two-year controlled study of fluphenazine decanoate and fluphenazine hydrochloride. Arch Gen Psychiatry 1979; 36 1283-94.

38 Kisely S, Campbell LA, Scott A, Preston NJ, Xiao J. Randomized and non-randomized evidence for the effect of compulsory community and involuntary out-patient treatment on health service use: systematic review and meta-analysis. Psychol Med 2007; 37: 3-14.

39 Hale T. Will the new antipsychotics improve the treatment of schizophrenia? BMJ 1993; 307: 749-50. 